\section{Weaving a social web}

\section{The Internet promises to revolutionize public engagement with science and technology.}

\section{David Dickson}

$\mathrm{M}$ odern communications technologies — in particular the Internet — have revolutionized the communication of scientific knowledge. But most interest has so far focused on their impact on the exchange of information between professional researchers, such as the development of electronic publication and the use of massive online databases.

Relatively little attention has been paid to the equally important issue of how these same communications technologies could transform the way in which this knowledge is disseminated to non-scientists, and the possibilities that open up for a new approach to the public understanding of science.

This approach offers an alternative to both the 'top-down' preaching and the carefully orchestrated 'dialogues' between scientists and 'the public' that are currently the most favoured forms of communication. In contrast, it promises a more grass-roots engagement in debates on the promises and limitations of modern science and technology.

The current imbalance in the use of the Internet to communicate scientific knowledge is understandable. The ease with which data can be shared electronically between researchers has many immediate and positive consequences for those both receiving and transmitting the information. This has encouraged significant investment.

By contrast, the use of the Internet to promote a true public understanding and appreciation of science faces significant hurdles. One is the question of access. It is ironic that those who stand to benefit most from the information that the Internet can provide are often those who lack the technical or financial resources to access it.

A second hurdle is that many efforts to use the Internet to communicate information about science and its impact on society have an implicit agenda. This is as true for the pressure groups that have so successfully used the web to promote campaigns on particular issues - from genetically modified

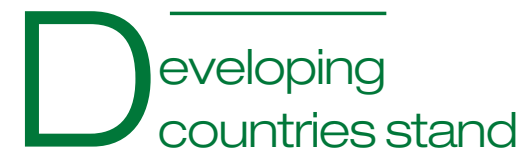

to benefit most from electronic distribution of information. crops to climate change - as it is for corporations that seek to counter what they characterize as 'propaganda' by mounting their own websites to present 'the facts'.

These hidden agendas can create their own problems. Think, for example, of South Africa's president, Thabo Mbeki, who claimed to have come across a significant scientific controversy over the relationship between HIV and AIDS during a late-night Internet surfing session when he happened upon a website that challenged the prevailing scientific consensus.

And then think not only of the way that some South African officials have used their president's views to justify limiting their efforts to combat HIV, but also of how they have accused manufacturers of anti-HIV drugs of using the web to try to stifle scientific debate in order to promote products in which they have a commercial interest.

We all stand to benefit from the exploration of ways to use the power of the Internet to disseminate reliable scientific and technical information. The effectiveness of a group engaged on any side of a public debate can only be enhanced by a sounder awareness of the scientific and technical dimensions of the disputed topic.

At the same time, as the case of HIV/AIDS underlines only too dramatically, we also need ways to ensure that the potential of the Internet for enhancing access to scientific information is exploited responsibly. Not because doing otherwise is morally damaging - there is no room here for censorship - but because, in thelong run, it is counter-productive.

Electronic scientific publication is now being recognized as requiring rules and procedures to ensure its legitimacy, even if these are different from those in place for printed scientific publications (see www.nature.com/ nature/debates/e-access). The same is true for electronic dissemination of information about science and technology, particularly when the information is of direct relevance to contentious issues.

There is a particular opportunity here to use the Internet to meet the social and economic needs of developing countries. These countries stand to benefit more than anyone from the reduced marginal costs of electronic dissemination - but also face many difficulties created by the continuing existence of a 'digital divide' between rich and poor.

Many experiments are needed to find the best way of doing this. One is SciDev.Net, a website, launched this week, devoted to delivering news and providing a forum for debate about the contribution - real, potential or

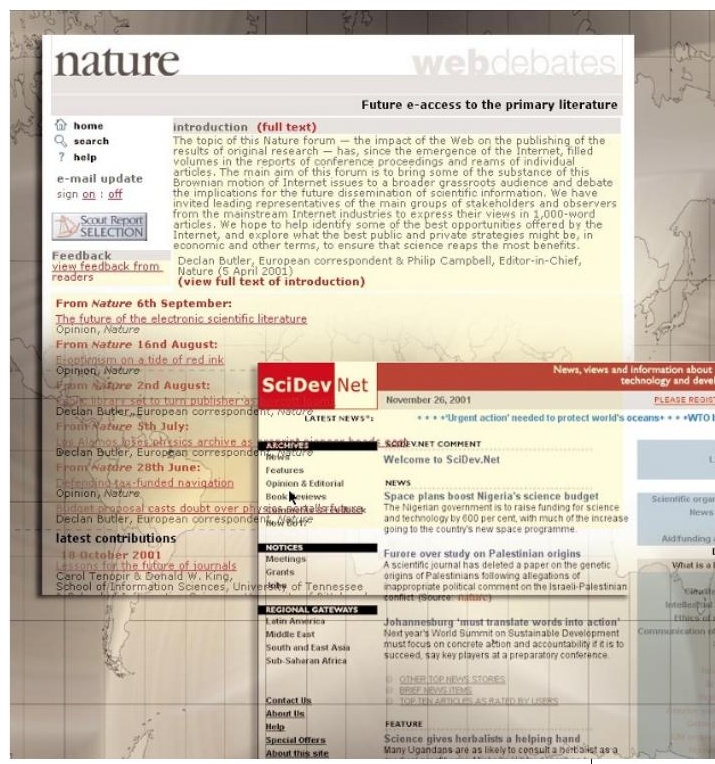

Outreach: how can scientific information best get to those who need it most?

contested - of science and technology to the needs of developing countries.

The website is being launched with the editorial backing of the journals Nature and Science, both of which have agreed to provide free access each week to relevant articles (selected by SciDev.Net editorial staff). It is being produced with the support of the Third World Academy of Sciences, and is financed by international aid agencies in Britain, Sweden and Canada.

Much of the new website uses a traditional approach to providing information about science, by publishing news items, features, contributed opinion articles and 'policy briefs', albeit in electronic form. In some cases, this material will be linked together in 'dossiers' aimed, for example, at policymakers and others looking for an authoritative overview of a topic.

The site will also seek to exploit new opportunities opened up by the web. It will, for example, allow instant comment and discussion about any item published on the site, and also provide a guided tour, using annotated links, of other relevant websites.

A key challenge to initiatives such as SciDev.Net is how to democratize the gathering and dissemination of information about science in a way that retains the legitimating devices of conventional editorial processes.

Providing this can be done, responsible and imaginative use of the Internet is an exciting way of matching the resources offered by science and technology directly to particular social needs. It is a possibility from which we all stand to benefit - but particularly those now excluded from enjoying the fruits of modern science in developed and developing countries alike.

David Dickson is the founding director of SciDev.Net and a former news editor of Nature.

i www.scidev.net 